\title{
0 formante do cantor e os ajustes laríngeos utilizados para realizá-lo: uma revisão descritiva
}

\author{
Cristina de Souza Gusmão (UEMG, Belo Horizonte, MG). \\ tina_gusmao@yahoo.com.br \\ Paulo Henrique Campos (UEMG, Belo Horizonte, MG) \\ paulocam@yahoo.com.br \\ Maria Emília Oliveira Maia (FEAD, Belo Horizonte, MG) \\ kiumaia@terra.com.br
}

\begin{abstract}
Resumo: Este estudo descreve, através da literatura da Fonoaudiologia e da Física Acústica, alguns aspectos relacionados à produção da voz, tais como o espectro do som como a frequência fundamental, os harmônicos, os formantes e também os ajustes laríngeos. A revisão de literatura inclui a descrição anátomo-fisiológica do aparelho vocal, suas funções e mecanismo para produção vocal. Descreve também os aspectos relacionados à espectografia do som, da localização dos formantes e de ajustes anatômicos e musculares para se obter o formante do cantor. Este estudo visa esclarecer conceitos e levantar questionamentos sobre o que ocorre na fisiologia vocal e o que é dito e aceito pelo senso comum sobre o formante do cantor.
\end{abstract}

Palavras-chave: voz; formante do cantor; canto; fonoaudiologia; fisica acústica.

\section{The singer's formant and the laryngeal adjustments used to realize it: a descriptive review}

Abstract: This study describes some voice production aspects, like sound spectrum as the fundamental frequency, harmonics, the formants and also the laryngeal adjustments through the phonoaudiology and acoustics literature. The literature review includes the anatomical and physiological description of the vocal apparatus, its functions and the mechanism for the vocal production. It also describes related aspects of the sound spectrographs, to the formants location and to the anatomical muscle adjustments to realize the singer's formant. This study aims at clarifying concepts and raising questions about what happens in vocal physiology and what is said and accepted by the common sense about the singer's formant.

Keywords: voice; singer's formant; singing; phonoaudiology; acoustics.

\section{Introdução}

A voz cantada é considerada uma das mais belas formas de expressão. 0 canto é conceituado como uma forma de comunicação através da qual o indivíduo é capaz de expressar os sentimentos escondidos na alma.

Segundo COSTA e SILVA (1998), é através da fala que os indivíduos se comunicam melhor e pelo canto se expressam artisticamente; como se pudessem dividir uma metade racional para a fala e outra emocional para ser transmitida pelo canto.

Dentre tipos diversos, o canto lírico é reconhecido pela sua estética particular, projeção vocal adequada, dinâmica e qualidade vocal agradável. Desta forma, observa-se que cantores eruditos têm maior preocupação e cuidados com seu instrumento de trabalho preocupando-se mais com a fisiologia vocal. Por isso iniciaremos este texto abordando alguns aspectos relacionados à produção vocal. Antes, porém, vale revisarmos algumas particularidades da laringe, determinantes na abordagem da produção vocal, que por ora nos propomos a realizar.

A laringe é um órgão situado na extremidade superior da traqueia e na região anterior do pescoço que se conecta, na parte inferior à traqueia e na superior abre-se à faringe. BEHLAU (2001), ZEMLIM (2000) e PINHO (2008) afirmam que o esqueleto da laringe é formado por cartilagens, músculos, membranas e mucosas, como se observa no Ex. 1 '. 


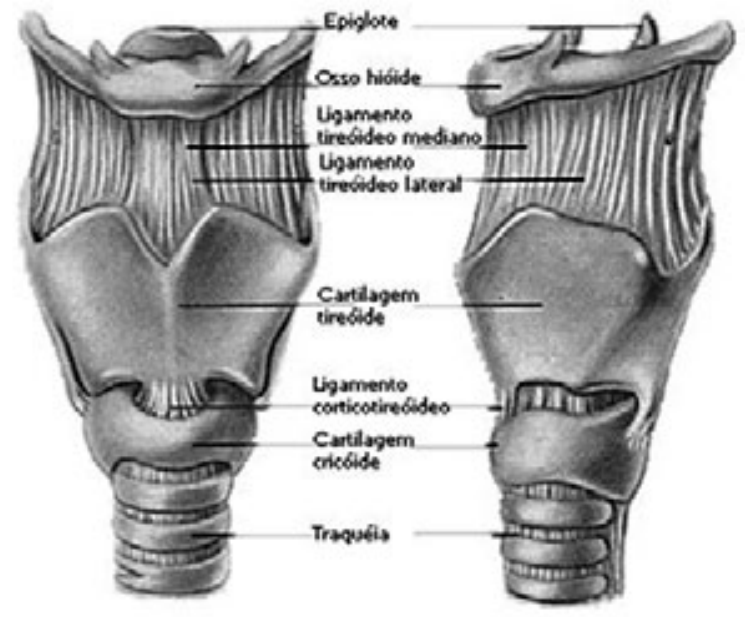

Ex.1 - Vista anterior e lateral da laringe

A laringe possui funções importantes para o ser humano, sendo elas a função respiratória, a deglutitória e a fonatória e tem como função principal proteger as vias aéreas inferiores (BEHLAU, 2001), ou seja, traqueia, pulmão, brônquios e bronquíolos. Além disso age como uma válvula denominada pregas vocais, cujo papel é impedir que corpos estranhos penetrem na laringe com o risco de causarem alguma infecção.

A laringe também tem uma função não-biológica de extrema importância para nós seres humanos, que é a emissão do som. Suas pregas vocais são capazes de produzir som quando o ar que sai dos pulmões (ar expiratório), passa por entre elas e faz produzir som através da vibração das mesmas. Desta forma, segundo BEHLAU (2001), o som produzido pelas pregas vocais amplifica-se ao passar pelas cavidades situadas acima da laringe, conhecidas como cavidades de ressonância, sendo elas: laringe, faringe, orofaringe e nasofaringe.

\section{Espectro do som: frequência fundamental, harmônicos e formantes.}

\subsection{Frequência fundamental}

A frequência fundamental é definida através da velocidade com que as pregas vocais vibram completando uma vibração ou um ciclo vibratório. A frequência fundamental pode ser definida pelo som inicial que as pregas vocais emitem numa fala habitual, ou seja, a frequência da fala de um indivíduo, ou também pela vibração de qualquer nota emitida mesmo que essa nota não esteja dentro do registro da fala habitual, como exemplo, o canto.

Levando em consideração a frequência da fala habitual, a frequência fundamental depende do sexo, da idade e do processo de mudança da voz do indivíduo, que ocorre na puberdade. Mas outros fatores podem interferir temporariamente nesse processo, a saber fatores comportamentais, emocionais e orgânicos.

A frequência fundamental depende diretamente do resultado natural do comprimento das pregas vocais, ou seja, do tamanho e também da velocidade em que as mesmas vibram (BEHLAU, 2001; ZEMLIN, 2000).

\subsection{Harmônicos}

0 sinal sonoro, "a voz" produzida na laringe, é muito complexo, pois é composto por uma frequência fundamental determinada pelo tamanho das pregas vocais, pela velocidade de vibração e por diversas frequências parciais, que são múltiplos integrais da frequência fundamental. Essas frequências parciais são conhecidas como harmônicos da frequência fundamental. Dessa forma, pode-se entender que se a frequência fundamental de um indivíduo é de $100 \mathrm{~Hz}$, ou seja, as pregas vocais vibram 100 vezes por segundo, a laringe inclui componentes que são múltiplos integrais de 100, sendo encontrados componentes de $100,200,300 \mathrm{~Hz}$ no sinal sonoro (ZEMLIN, 2000), como se observa no (Ex. 2) ${ }^{2}$. Alguns destes harmônicos, ao chegar às cavidades de ressonância, possuem compatibilidade com a frequência do trato vocal. Dessa forma, estes sons que foram transferidos mais facilmente pelo trato vocal são amplificados e transformados em formantes, sendo este o agrupamento de harmônicos (CORDEIRO, PINHO e CAMARG0, 2007; BEHLAU, 2001). MILLER (1996) $^{3}$, apud VIDAL (2000) e ZEMLIN (2000), relatam que o trato vocal é composto pela cavidade oral, faríngea e, às vezes pela cavidade nasal. Já BEHLAU (2001) e PINHO (2003) relatam que o trato vocal é composto pela cavidade oral, nasal, nasofaringe, orofaringe e laringe, sendo que para estas autoras as cavidades nasal e paranasal entram como parte integrante do trato vocal.

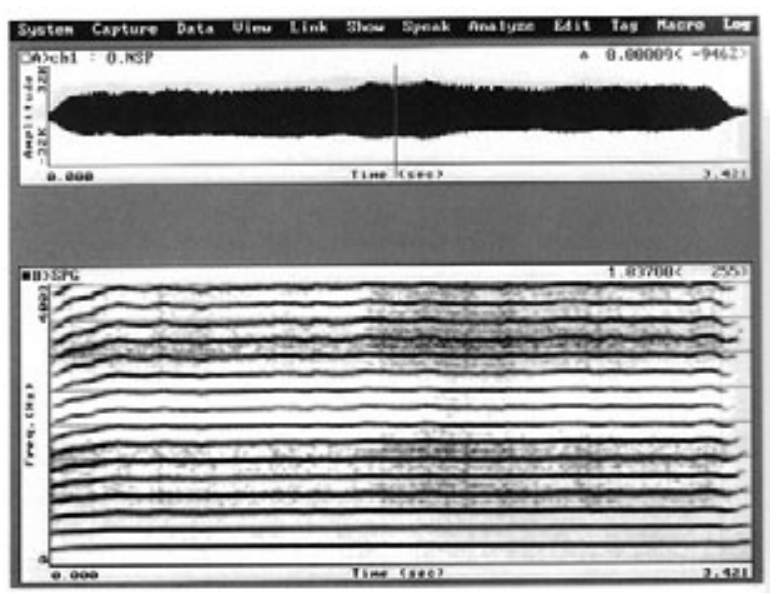

Ex.2 - Espectro do som com sua frequência fundamental e seus harmônicos.

\subsection{Formante}

0 formante é representado pelas frequências naturais de ressonância do trato vocal, especificamente na posição articulatória da vogal falada. As vogais são identificadas pelos seus formantes (BEHLAU, 2001). Os formantes determinam a qualidade das vogais e contribuem muito para 0 timbre pessoal do cantor (CORDEIRO, PINHO E CAMARGO, 2007). Sendo assim, em uma análise acústica, observa-se que os primeiros cinco formantes são os de maior interesse, sendo que os três primeiros são responsáveis pela identidade das vogais e possuem características instáveis, já que podem apresentar variações de vogal para vogal, enquanto que o quarto e o quinto formantes não têm a mesma variação, sendo então considerados estáveis (MARTER, 2005), 
e são responsáveis pelo timbre pessoal, ou seja, pela qualidade e brilho da voz (BEHLAU, 2001).

Sobre essa questão, MEDEIROS (2004) ressalta que há uma diferença entre o padrão formântico das vogais faladas em relação às vogais cantadas. 0 que se observa é que na vogal cantada há uma distorção do formante, tanto acusticamente quanto articulatoriamente em relação à vogal falada, ocorrendo uma sobreposição do primeiro formante das vogais [a], [e] e [o]. Dessa forma fica sendo responsabilidade do segundo formante a diferenciação acústica dessas vogais, já que não se observa a sobreposição do segundo formante.

Os formantes, na maioria das vezes, são expressos através de seu valor médio em Hertz $(\mathrm{Hz})$, ou ciclos por segundo, e designados por $F_{1} F_{2} F_{3} F_{n}$ de modo progressivo (BEHLAU, 2001). De acordo com DINVILLE (1993: 45), "os formantes são frequências que servem para determinar o timbre". DINVILLE (1993) e CORDEIRO, PINHO e CAMARGO (2007) descrevem ainda a localização no trato vocal de cada formante, afirmando que o primeiro formante $\left(F_{1}\right)$ ocorre na cavidade posterior da boca e está em torno de 250 a 700 Hz. DINVILLE (1993) afirma que o segundo formante $\left(F_{2}\right)$ fica situado na cavidade oral entre os valores de 700 a $2.500 \mathrm{~Hz}$. Já CORDEIRO, PINHO e CAMARGO (2007) concordam que o segundo formante fica localizado na parte anterior da cavidade oral.

Segundo as autoras, CAMARGO e CUKIER (2005), o primeiro formante $\left(F_{1}\right)$ está relacionado à abertura da boca e à altura da língua na cavidade oral, e o segundo formante $\left(F_{2}\right)$ tem relação com o deslocamento ântero-posterior da língua. Já para SUNDBERG (1987) ${ }^{4}$, apud BARRICHELO (2007), o primeiro formante $\left(F_{1}\right)$ é sensivel à abertura da mandibula, já que quanto maior a abertura da boca, mais aguda fica a frequência do formante.

Para MAGRI, CUKIER, KARMAN e CAMARGO (2007), as frequências dos três primeiros formantes determinam a identidade fonética da vogal, especialmente a dos dois primeiros. Como se observa no Ex. $3^{5}$.

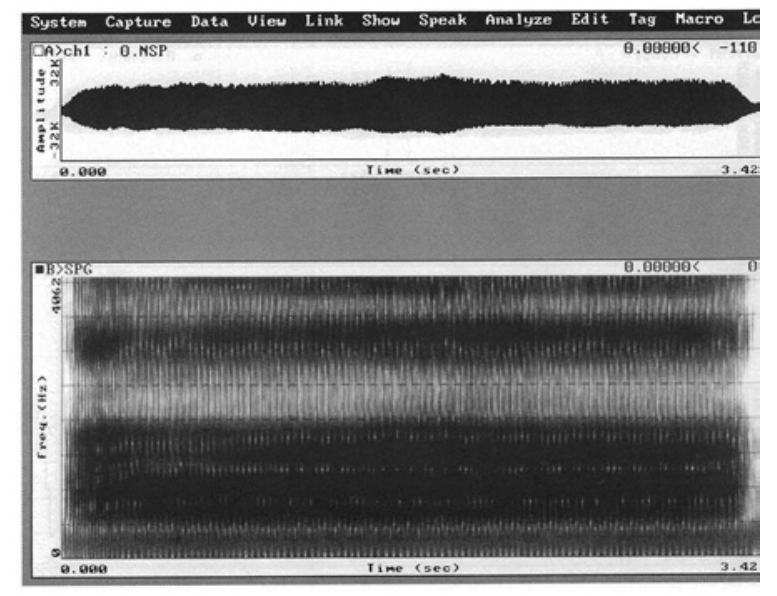

Ex.3 - Espectro sonoro da vogal [a] sustentada formando o formante (barras escurecidas no espectro).
Para CORDEIRO, PINHO e CAMARGO (2007), o quarto formante $\left(\mathrm{F}_{4}\right)$ provavelmente tem ligação com o comprimento do tubo laríngeo; o (Ex. 4$)^{6}$ tenta demonstrar este fenômeno.

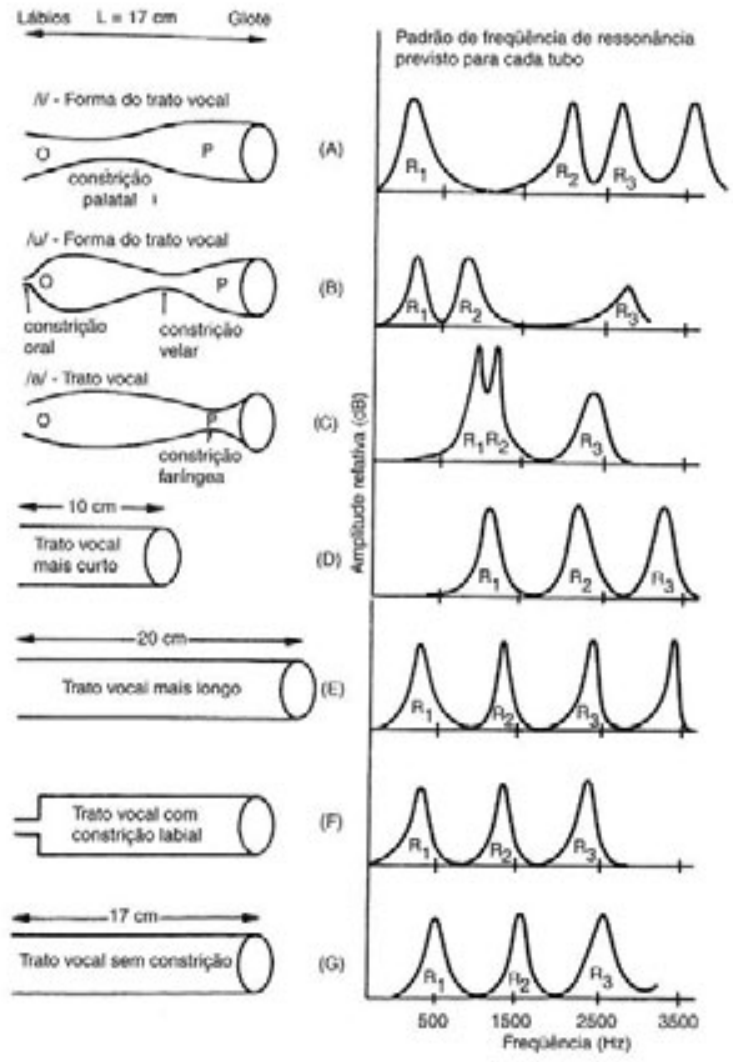

Ex.4 - Esquema da distribuição dos formantes das vogais [i], [u] e [a], em tratos vocais distintos em comprimento e com constrição nos vários locais do trato vocal.

\section{Formante do cantor}

A laringe, através da voz cantada, é o primeiro instrumento musical utilizado pelo ser humano. 0 cantor treinado tem a capacidade de sobressair-se ao som de uma orquestra sem fazer uso de amplificação sonora como o microfone e sem prejudicar seu aparelho fonador. Desta forma, obtém uma voz clara, com brilho, rica em harmônicos, com boa articulação e vibrante. Na maioria das vezes, o responsável por alguns destes aspectos é o formante do cantor (CORDEIRO, PINHO e CAMARGO, 2007).

0 formante do cantor é encontrado geralmente em vozes com treinamentos específicos do canto erudito e é definido pela amplificação sonora das frequências de 2.000, 3.000 e $4.000 \mathrm{~Hz}$, sendo demonstradas no espectro acústico pela junção do terceiro, quarto e quinto formante. Isso se deve à sua localização na região aguda e ao elevado pico de amplitude, desta forma, não se tem a ocorrência de outras vozes ou mesmo dos instrumentos da orquestra (BEHLAU, 2001 e CORDEIRO, PINHO e CAMARGO, 2007). Segundo FANT (1970) ${ }^{7}$, apud CORDEIRO, PINHO e CAMARGO (2007), o trato vocal, através do controle ativo no canto, pode incrementar de 3 a $5 \mathrm{~dB}$ 
na amplitude das frequencias agudas, além do acréscimo natural de 10 a $15 \mathrm{~dB}$ já existente.

A técnica lírica é utilizada pelos cantores de ópera, por isso suas vozes apresentam um pico espectral intenso e largo em torno de $3.000 \mathrm{~Hz}$. É este pico que proporciona aos harmônicos uma maior amplitude e o agrupamento destes harmônicos - os formantes - possibilita o destaque da voz sobre o som da orquestra. Para VIEIRA (2004), o responsável por este fenômeno é o formante do cantor; o autor afirma ainda que a ocorrência deste fenômeno está relacionada ao abaixamento da laringe e o alargamento da cavidade faríngea, embora este não seja o único mecanismo existente.

DINVILLE (1991) diz que, para se obter o formante do cantor, a laringe deve elevar-se ao atingir um som agudo e em seguida descer para o grave. ZEMLIM (2000), por sua vez, afirma que ao se abaixar a laringe ou alargar a faringe, o individuo faz com que os formantes fiquem mais graves, produzindo então uma voz com um timbre mais escuro. Portanto, é importante ressaltar que um ajuste vocal controverso, ou que foge da fisiologia vocal, pode prejudicar o aparecimento ou a definição do formante do cantor. Isso explica a grande complexidade deste assunto e as divergências entre os autores sobre um mesmo parâmetro.

SUNDBERG (1974) relata que o formante do cantor - a junção do quarto e do quinto formante- pode ser denominado como uma ressonância adicional que diferencia o canto da fala. É o responsável pela percepção de "brilho" e projeção da voz que possibilita a sua perfeita percepção na presença de toda uma orquestra. Relata ainda que o aparelho fonador isolado já tem sua própria estrutura formântica. Por isso atua como um ressonador independente gerando um formante adicional entre o terceiro e o quarto formante. Afirma ainda que o nível de pressão sonora (NPS) do formante do cantor depende de vários fatores, dentre eles, o NPS total da emissão.

Conforme as perspectivas mencionadas até o presente momento, podemos notar que existe controvérsia em relação às cavidades onde ocorre o formante do cantor e quais estruturas são utilizadas para realizá-los. SUNDBERG (1974) cita que a formação do quarto e do quinto formante depende do comprimento de todo o trato vocal e da configuração na profundidade da faringe. 0 autor defende, também, que o terceiro formante tem ligação com o movimento da língua. Para CORDEIRO, PINHO e CAMARGO (2007), o que favorece o aparecimento do formante do cantor é o agrupamento de todas as estruturas formando um tubo único, acoplando o terceiro, o quarto e quinto formante.

Para se obter qualquer formante, é necessária a produção de harmônicos gerados pela mucosa das pregas vocais. Sendo assim, os harmônicos só serão amplificados se as pregas vocais produzirem os harmônicos correspondentes à sua faixa de frequência. Com isso, é possivel afirmar que a produção de qualquer formante está ligada à integridade da mucosa das pregas vocais, e que patologias que levam à diminuição na produção destes harmônicos dificultam a produção dos formantes, (CORDEIRO, PINHO e CAMARGO, 2007).

É importante salientar que a intensidade do formante do cantor também ocorre quando o cantor aumenta a intensidade propositalmente, o que significa que uma maneira simples de se criar o formante do cantor é simplesmente cantar mais forte, ou seja, com mais intensidade. No entanto, isso pode causar vários problemas vocais na maioria das vezes.

\section{Os ajustes laríngeos}

A deficiência técnica de cantores não treinados, a grande busca por projeção e brilho na voz e suporte respiratório deficiente podem acarretar várias tensões musculares como, por exemplo, a constrição da musculatura situada acima da laringe conhecida como supraglótica, além da tensão das pregas vocais e a redução de seu movimento, o que pode muitas vezes explicar a ausência do formante do cantor em alguns cantores, (CORDEIRO, PINHO e CAMARGO, 2007).

0 primeiro, segundo e terceiro formantes definem as vogais, e o quarto e o quinto formantes definem o timbre e a qualidade da voz, conhecido como formante do cantor, e essa definição depende da localização do formante no trato vocal. A literatura aponta alguns ajustes laríngeos corretos para se obter o formante do cantor. Nesse contexto, podemos incluir o abaixamen-

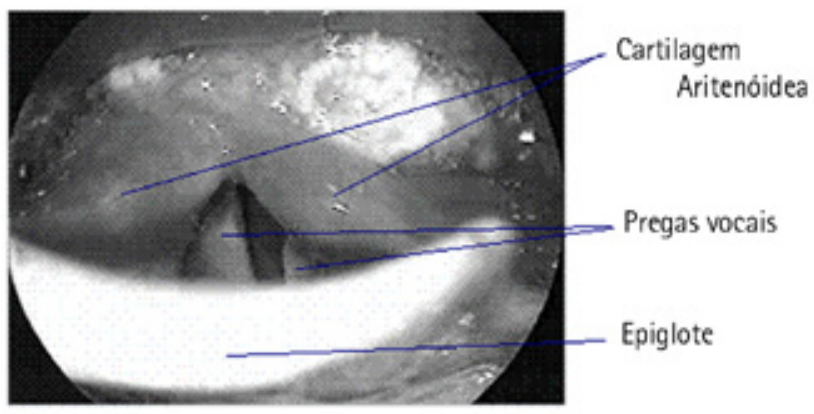

Ex.5 - Cartilagem aritenóidea e cartilagem epiglótica se aproximando para fazer a constrição ariepiglótica. 
to da laringe, o alargamento da cavidade faríngea, a constrição ariepiglótica, sendo esta a aproximação das cartilagens aritenóidea e epiglótica (Ex.5) ${ }^{8}$, o alongamento do tubo faríngeo e, por fim, a expansão de todo o trato vocal. Segundo BEHLAU (2001), estes são alguns dos ajustes que levam à junção do terceiro, quarto e do quinto formantes.

Já SUNDBERG (1974) afirma que a ocorrência do formante do cantor depende de um abaixamento da laringe e do alargamento da faringe, para que haja aumento de algumas cavidades situadas na laringe. Alguns autores como CORDEIRO, PINHO e CAMARGO (2007) consideram que o tamanho do trato vocal interfere diretamente na produção do formante e que tratos vocais maiores enfatizam as frequências graves, e os menores enfatizam as frequências agudas.

FANT (1970) ${ }^{6}$ apud CORDEIRO, PINHO e CAMARGO (2007) fazem uma relação dos formantes na qual afirmam que 0 terceiro formante ocorre devido a uma constrição ocorrida no percurso do som e que o quarto formante se relaciona ao comprimento da laringe.

É importante ressaltar que todos os autores citados relatam sobre a localização dos formantes, (BEHLAU, CORDEIRO, PINHO e CAMARGO, 2007; DINVILLE, 1991; SUNDBERG, 1974; PINHO e TSUJI, 1995), e isso indica, por um lado, que a integridade de todas as estruturas favorece 0 formante do cantor e determina a qualidade sonora do cantor. Por outro lado, isso indica que a falta da integridade pode ser a causa da ausência do mesmo.

É muito comum, no canto lírico, a busca por uma "cavidade de ressonância" que proporcione uma voz agradável e com muita projeção. Existem pesquisas que relatam que no canto lírico ocorre uma posteriorização do ponto articulatório, ou seja, (a posteriorização da língua para se fazer determinado fonema) buscando assim uma ressonância posterior, pois a concentração sonora ficará concentrada na cavidade posterior da boca. Além disso, ainda temos a verticalização da mandíbula e elevação do véu palatino, ou seja, palato mole. (PERELLÒ, $1975^{9}$ e PILLOT ${ }^{10}, 1996$ apud CORDEIRO, PINHO e CAMARGO, 2007). Para SUNDBERG (1974), a busca de uma ressonância posterior faz com que ocorra um rebaixamento do segundo formante, já que a lingua encontra-se posteriorizada.

A constrição ariepiglótica e a abertura da laringe associadas ao alongamento circular de toda a faringe, citado por alguns autores (PINHO e TSUJI, 1995 e SUNDBERG, 1974), não são os únicos mecanismos responsáveis pela criação do formante do cantor, mas possivelmente podem levá-lo ao centro de frequência ideal para o surgimento deles, e isso explica a divergência de alguns autores quanto ao centro de frequência do formante ter, ou não, relação com a classificação vocal no canto (CORDEIRO, PINHO e CAMARGO, 2007).

\section{Discussão}

Para nos posicionarmos mediante essa discussão, é importante lembrar que há uma controvérsia na literatura sobre a localização dos formantes na cavidade oral. Algumas autoras, como DINVILLE (1993) e CORDEIRO, PINHO e CAMARGO (2007), relatam que o primeiro formante (F1) ocorre na cavidade posterior da boca e está em torno de 250 a $700 \mathrm{~Hz}$. CAMARGO e CUKIER (2005) e MAGRI, CUKIER, KARMAN e CAMARGO (2007) já citam que o primeiro formante (F1) está relacionado com a altura e com o deslocamento da língua no plano vertical e com a abertura da boca.

Desta forma, pode-se dizer que a abertura da boca, seja no plano vertical ou horizontal, influencia a produção do primeiro formante, e a altura da língua na cavidade oral também. Isso parece indicar, talvez, que a produção de uma vogal com a língua anteriorizada desfavoreça o primeiro formante.

Em relação ao segundo formante (F2), CORDEIRO, PINHO e CAMARGO (2007) concordam que fica localizado na cavidade oral anterior. CAMARGO e CUKIER (2005), por outro lado, relatam que o segundo formante (F2) ocorre devido ao deslocamento da língua no plano horizontal, ou seja, com o grau de variação no sentido ântero-posterior. Assim, podemos verificar novamente que a posição da língua, agora horizontalmente, influencia na produção deste formante.

Podemos verificar então que ambos os formantes são produzidos pelos mesmos órgãos, entretanto, esses órgãos utilizam posicionamentos diferentes para produzi-los.

Já o terceiro formante (F3) está relacionado com a cavidade atrás da constrição da língua e aquela à frente dela (CAMARGO e CUKIER, 2005). Ou seja, cavidade faríngea e cavidade oral anterior.

E, para MAGRI, CUKIER, KARMAN e CAMARGO (2007), o quarto formante (F4) relaciona-se ao formato da laringe e da faringe na mesma altura, mas Cordeiro, PINHO e CAMARGO (2007) dizem que o quarto formante provavelmente tem ligação com o comprimento do tubo laríngeo. Assim, novamente, autores relatam localidades diferentes para a produção do mesmo formante. 0 importante é que, se o quarto formante já tem relação com o formante do cantor, e que o formante do cantor determina o brilho, qualidade e projeção da voz, acreditamos que o comprimento do tubo laríngeo tenha uma grande influência na produção deste formante já que o trato vocal influencia na produção dos harmônicos e consequentemente da produção do formante.

É quase unânime entre os autores consultados que o primeiro (F1), segundo (F2) e o terceiro (F3) formantes são responsáveis pela identificação das vogais. Enquanto que os outros dois, o quarto (F4) e o quinto (F5) são responsáveis pela qualidade vocal e timbre da voz (Formante do cantor). Mas CORDEIRO, PINHO e CAMARGO (2007) e 
BEHLAU (2001) concordam que o terceiro formante (F3) seja responsável pela qualidade e brilho na voz, pelo que, para estas autoras, o formante do cantor é a junção do terceiro, quarto e quinto formantes.

Em relação ao quinto formante (F5), não encontramos na literatura pesquisada qualquer referência a algum local para a sua produção porque há uma concordância entre alguns autores sobre o formante do cantor ocorrer graças à junção do terceiro, quarto e do quinto formantes (CORDEIRO, PINHO e CAMARGO, 2007 e BEHLAU, 2001).

Outra discussão que é relevante neste trabalho diz respeito aos ajustes laríngeos para a realização do formante do cantor. VIEIRA (2005) e SUNDBERG (1974) ponderam que um dos ajustes utilizados para este fenômeno é o abaixamento da laringe e o alargamento da cavidade faríngea. Há também a afirmação de CORDEIRO, PINHO e CAMARGO (2007) quando relatam que o aparecimento do formante do cantor se deve ao agrupamento de todas as estruturas formando um único tubo, acoplando o terceiro, o quarto e o quinto formantes. A expansão de todo o trato vocal citada por BEHLAU (2001) e ao comprimento da laringe (FANT, 1970 apud CORDEIRO, PINHO e CAMARGO, 2007).

É importante ressaltar que todos estes recursos citados acima favorecem o aparecimento do formante do cantor, já que todos priorizam um tubo ressonador para a produção dos formantes.

Outros autores, PINHO e TSUJ (1995), encontraram a ocorrência de constrição ariepiglótica e abertura do vestíbulo laríngeo, e SUNDBERG (1974) fala da abertura do vestíbulo laríngeo associada ao alargamento circular da faringe, ou seja, mais uma vez a utilização de recursos que favoreçam o alargamento do tubo laríngeo.

Cada autor trata de ajustes ideais para a realização do formante do cantor, mas o interessante é que todos buscam um mesmo objetivo: favorecer a projeção e a facilidade dos harmônicos para se obter formantes com brilho e qualidade como o encontrado no formante do cantor, e este mecanismo, segundo os autores citados acima, acontece quando se tem um aumento e alargamento de todo o trato vocal. Neste caso, há concordância entre os autores sobre os ajustes para se obter o formante do cantor.

É de extrema importância relatar que todos os autores pesquisados citam o trato vocal como sendo o grande responsável pela formação do formante do cantor e mencionam também ser ele o responsável de se obter um tubo único que amplifica toda a voz. Com exceção de BEHLAU (2001) e de PINHO (2003) e PINHO (2008), nenhum dos autores pesquisados tratam das cavidades paranasais como sendo parte integrante do trato vocal. Tal posição contradiz o senso comum sobre a voz passar pelas cavidades de ressonância incluindo as cavidades paranasais conhecida como voz na máscara para obter brilho e projeção vocal. Porém, a ideia de voz na máscara ajuda muito na compreensão de aspectos subjetivos da sensação sonora principalmente no canto, mas não podemos deixar de pensar que a voz ocorre por um processo fisiológico e que distorções neste aspecto podem prejudicar e muito toda ideia de uma voz fácil, sem tensão, com qualidade e projeção.

\section{Considerações finais}

0 formante do cantor é um tema ainda pouco discutido na literatura fonoaudiológica o que torna difícil seguir uma única linha de raciocínio para sua abordagem. Apesar disso, este trabalho nos proporcionou conhecimentos relevantes sobre esse tema fascinante que é o formante do cantor, como a produção dos formantes, sua localização e definição, além de ressaltar sobre os ajustes laríngeos utilizados para realizá-los.

Além disso, levantou questões do senso comum, como por exemplo, "voz na máscara", ressonância nasal, recursos estes utilizados para adquirir qualidade vocal, projeção e brilho na voz. Dentre os autores pesquisados, a ressonância paranasal foi apontada por BEHLAU (2001) e PINHO (2003) como sendo uma cavidade que favorece o formante do cantor. TITZE (2001) ressalta que as sensações vibratórias percebidas na face nada mais é do que a conversão de energia aerodinâmica em energia acústica; e não um som ressoado na cavidade nasal e seios paranasais como erroneamente se faz referência. Ou seja, para este autor a voz na cavidade nasal e paranasal nada mais é do que uma sensação sonora. Mas há uma concordância de que o trato vocal como sendo um tubo único favorece todos requisitos dados ao formante do cantor.

É de suma importância para a literatura musical e fonoaudiológica, que novos pesquisadores discutam sobre este tema e que novos estudos sejam realizados a fim de se compreender melhor este mecanismo pouco discutido. Através do levantamento de novos estudos, também se torna possivel esclarecer questões levantadas pelo senso comum, que são importantes e imprescindiveis como parte de um processo pedagógico.

Mas não podemos deixar de pensar que este assunto deva ser discutido considerando a fisiologia vocal e a física acústica, pois, só assim, teremos embasamento científico e fidedigno desse tema que tanto interessa aos cantores, professores de canto e fonoaudiólogos. 


\section{Referências}

BARRICHELO, Viviane, M.O. Voz ressoante em alunos de teatro: correlatos perceptivo-auditivo e acústicos da emissão treinada Y-Buzz de Lessac. Tese de mestrado apresentado a Universidade Federal de São Paulo. Escola Paulista de Medicina. Programa de Pós-graduação em Distúrbios da comunicação humana. 112f. São Paulo, 2007.

BEHLAU, Mara, MADAZIO, Glaucya, FEIJO, Deborah, PONTES, Paulo.Avaliação de Voz .In: BEHLAU, Mara. Voz o livro do especialista. V. 1. Rio de Janeiro: Revinter, 2001. Capitulo 3. p. 130-164.

CORDEIRO, Gislaine Ferro; PINHO, Silvia M. R; CAMARGO, Zuleica Antonia. Formante do cantor - um enfoque fisiológico. In: PINHO, Silvia M R.Temas em voz profissional. São Paulo: Revinter, 2007. p.23-30.

COSTA, H 0, SILVA, M A de. Voz Cantada. São Paulo: Lovise, 1998.

CUKIER, Sabrina; CAMARGO, Zuleica. Abordagem da qualidade vocal em um falante com deficiência auditiva: aspectos acústicos relevantes do sinal de fala: Revista CEFAC, São Paulo, V. 1, n. 7, jan-mar. p. 93-101, 2005.

DINVILLE, C. A técnica da voz cantada. 2. ed. Rio de Janeiro: Enelivros, 1993.

MAGRI, Aline; CUKIER-BLAJ, Sabrina; KARMAN, Delmira de Fraga e; CAMARGO, Zuleica Antônia de. Correlatos perceptivos e acústicos dos ajustes supraglóticos na disfonia. Revista CEFAC. São Paulo. v. 9 n.4. Oct/Dec, 2007.

MARTER, Suely. Análise acústica e perceptivo-auditiva da voz de atores e não atores masculinos: Long term average spectrum e o "formante do ator".2005, 148 f. (Doutorado em distúrbios da comunicação humana) - Escola Paulista de Medicina, Universidade Federal de São Paulo, São Paulo, 2005.

MEDEIROS, Beatriz Raposo de. 0 português brasileiro e a pronúncia do canto erudito: reflexões preliminares. ARTEunesp. v. 16, p.47-55. 2003-2004.

PINHO, Silvia, TSUJI, DH. Avaliação funcional da laringe em cantores. Acta Awho, 15 (2): 87-93. 1995.

PINHO, Silvia; CAMARGO, Zuleika. Introdução à análise acústica da voz e da fala. In: Pinho, Silvia. Tópicos em voz. Rio de Janeiro: Guanabara Koogan, 2001. Capítulo 2. p.19-38.

PINHO, Silvia M. Rebelo. Avaliação e Tratamento da Voz In: PINHO, Silvia M. Rebelo. Fundamentos em Fonoaudiologia. Rio de Janeiro: Guanabara Koogan, 2003. p.11-12.

PINHO, Silvia M. Rebelo; PONTES, Paulo. Músculos intrínsecos da laringe e dinâmica vocal. Rio de Janeiro: Revinter, 2008. p.8 e 10.

SUNDBERG J. Articulatory interpretation of the singing formant. Journal of the Acoustical. Society of Americana, 1974. 55: 838-844.

TITZE, I.R. Acoustic Interpretation of Resonant Voice. Journal of Voice. 2001; 15(4): 519-528.

VIEIRA, M.N. Uma introdução à acústica da voz cantada. In: I Seminário Música, Ciência e Tecnologia. 2004, São Paulo. AcMUS - I Seminário Música, Ciência e Tecnologia, 2004. v.1 p. 70-79.

VIDAL. Mirna R de M. Pedagogia vocal no Brasil: Uma abordagem emancipatória para o ensino-aprendizagem do canto. 2000,152 f. (mestrado em Música) Centro de Letras e Artes. Universidade do Rio de Janeiro, Rio de Janeiro, 2000.

ZEMLIN, Willard R. Anatomia e Fisiologia aplicada a fonoaudiologia 4. ed. Porto Alegre: Artmed, 2000.

\section{Leitura recomendada}

ANDRADE, Simone Rattay; FONTOURA, Denise Ren da; CIELO, Carla Aparecida. Inter-Relação entre Fonoaudiologia e Canto: Revista Música Hodie, Goiânia, V. 7, n. 1. p. 83-98, 2007.

FONOAUDIOLOGIA.COM: Um método de investigação dos distúrbios da fala e voz: A espectografia vocal. Desenvolvido por HORTA, Leila; TOMITA, Shiro, 2001. Apresenta informações direcionadas ao profissional de Fonoaudiologia. Disponivel em: <http://www.fonoaudiologia.com/trabalhos/artigos/artigo-027/index.htm>. Acesso em: 4 jun. 2008.

HUCHE, F.l; ALLALI,A. A voz. Anatomia e fisiologia dos órgãos da voz e da fala. 2. ed. Porto Alegre: Artmed, 1999. V. 1.

ZAMPIERI, Sueli A; BEHLAU, Mara; BRASIL Osíris OC do. Análise de cantores de baile em estilo de canto popular e lírico: perceptivo-auditiva, acústica e da configuração laríngea. Revista Brasileira de Otorrinolaringologia. São Paulo. V. 68 n.3, p. 378-86, maio/jun. 2002.

Cristina de Souza Gusmão é Fonoaudióloga clínica graduada pela FEAD - Minas desde 2006, especialista em Voz pela PUC- Minas desde 2007. Graduada em Música com habilitação em canto pela Universidade do Estado de Minas Gerais (UEMG) desde 2008. Atualmente trabalha com Assessoria e consultoria com profissionais da voz. É cantora integrante do grupo experimental de ópera da UEMG (GEL), professora de canto e preparadora vocal. Participa ativamente de palestras e oficinas relacionadas a voz profissional, principalmente com cantores, além de lecionar cursos de Oratória.

Paulo Henrique Campos é Licenciado em História pela Faculdade de Filosofia, Ciências e Letras de Belo Horizonte, 1997. Bacharel em Música com Habilitação em Canto pela Escola de Música da UEMG, 2001. Especialista em práticas interpretativas da Música Brasileira pela Escola de Música da UEMG, 2003 e possui o título de mestre em educação musical 
pela Escola de Música da UFMG concluído em Março de 2007. Professor da UEMG nas áreas de canto, fisiologia da voz e pedagogia do ensino de canto desde 2002. Como regente Paulo Henrique Campos atua à frente do "Coral Imprensa Oficial" desde 2000. Além de atuar como músico efetivo da Fundação Clóvis Salgado desde 1995.

Maria Emilia Oliveira Maia é Fonoaudióloga graduada pela FEAD - Minas - 2006, especialista em Voz pelo Centro de Estudos da Voz - CEV - São Paulo, graduada em Psicologia pela Universidade Fumec - BH - 1989, especialista em Psicologia clínica pelo Conselho Federal de Psicologia. Atua em atendimento clínico com Assessoria e consultoria ao profissional da voz.

\section{Notas}

1 Figura disponivel em: <www. agmarrazes.ccems.pt/.../s-resp/v-resp-total.htm>. Acessado em 27-07-08

2. Figura disponivel em: SILVIA e CAMARG0, 2001 p.36

3 MILLER, R. The structure of singing - system and Art in vocal technique. New York: schirmer Books, 1996.

4 SUDBERG. J. The Science of the singing voice. Northern Illinois University Press; 1987.

5 Figura disponivel em: SILVIA e CAMARGO, 2001 p. 38.

6 Figura disponivel em: ZEMLIN, 2000. p. 320.

7 FANT, G. Acoustic theory of speech production. Paris: Mouton, 1970.

8 Figura disponivel em: <www.scielo.br/img/revistas/rboto/v72n6/a18fig01.gif >.Acessado em 06-10-08

9 Perellò J. Canto-Dicción: Foniatria estética. Barcelona: Editorial científico médica, 1975.

10 PILLOT C, Quattocchi S. Mesires acoustiques, jugements perceptifs et correlates physiologiques du singing-formant chez les chanteurs et les chanteuses lyriques. Rev Laringol Otol Rhinol. 1996; 117 (4): 335-9. 